\title{
A TEORIA DO DESTINO MANIFESTO: REVISITANDO OS CICLOS DA HISTÓRIA AMERICANA E O GOVERNO TRUMP'
}

\author{
THEORY OF MANIFEST DESTINY: REVIEWING THE CYCLES OF AMERICAN \\ HISTORY AND THE TRUMP GOVERNMENT
}

DOI: $10.5380 / \operatorname{cg} . v 10 i 2.78590$

Jonas Abreu²

\begin{abstract}
Resumo
A recorrente controvérsia sobre o significado da América demonstra os dois fios trançados desde a fundação do país: a ideia dos Estados Unidos como "experimento democrático", carregado de riscos e problemas, e o "destino manifesto", o fervor patriótico que conduz os americanos a sua autoproclamação como povo eleito, incumbido de uma missão divina. Este artigo analisa, no plano geral, as manifestações do destino manifesto na experiência americana e, em particular, no governo de Donald Trump. O estudo foi delineado conforme as premissas de um ensaio, por conta de sua característica discursiva, argumentativa e expositiva. Utilizando os métodos de pesquisa exploratória e revisão bibliográfica, examinou-se os ciclos da história americana nos quais são confrontadas de forma alternada essas duas tendências. Discutiu-se as evidências e o nível de envolvimento do destino manifesto no governo Trump em termos religiosos, econômicos e culturais. Investigou-se um amplo encadeamento de percepções, desde as críticas a respeito da Teoria da América até a compreensão do destino manifesto como princípio justificador do processo de expansão territorial e ideológico dos EUA. A pesquisa constatou, na política interna e externa do governo Trump, tanto a narrativa messiânica do destino manifesto como alguns dos fundamentos geopolíticos e econômicos que caracterizam os governos conservadores americanos. Concluiu-se que o ar de originalidade e a ostentação desse governo precisam ser relativizados, pois suas ações, incluindo as evidências do destino manifesto, constituem aspectos retornáveis dos ciclos da história americana.
\end{abstract}

Palavras-Chave: Ciclos da história americana; Destino manifesto; Trumpismo; Teoria da América; Liberalismo e Conservadorismo.

\begin{abstract}
The reocurring controversy over the meaning of America demonstrates the two strands twisted since the country's founding: the idea of the United States as a "democratic experiment" laden with risks and problems and the "manifest destiny", the patriotic fervor that leads Americans to their self-proclamation as an elected people, entrusted with a divine mission. This article looks at the general plan, the manifestations of destiny manifest in the American experience and in particular, in the administration of Donald Trump. The study was designed according to the premises of an essay, due to its discursive, argumentative and expository characteristics. Using the methods of exploratory research and literature review, we examined the cycles of American history in which these two trends are confronted alternately. The evidence and the level of involvement of the destiny manifested in the Trump administration in religious, economic and cultural terms were discussed. A wide range of perceptions was investigated, from criticisms about the Theory of America to the understanding of the manifest destiny as a justifying principle of the process of territorial and ideological expansion in the USA. The research found in the Trump administration's internal and foreign policy, both the messianic narrative of manifest destiny, as well as some of the geopolitical and economic foundations that

\footnotetext{
${ }^{1}$ Este artigo está licenciado sob a Licença Creative Commons Attribution (CC BY 4.0), sendo permitido o compartilhamento com reconhecimento da autoria e publicação inicial nesta revista.

${ }^{2}$ Mestrado em Bens Culturais e Projetos sociais (FGV), especialização em marketing (UCAM). Graduando em Administração. Coordenador técnico da Faetec Ipanema - Rio de Janeiro. E-mail: jonasabreu91@yahoo.com.br. ORCID: https://orcid.org/o000-0002-0203-5835.
} 
characterize American conservative governments. It was concluded that the air of originality and ostentation of this government needs to be relativized, since its actions, including the evidences of the manifest destiny, are returning aspects of the cycles of America history.

Keywords: Cycles of American history; Manifest Destiny; Trumpism; Theory of America; Liberalism and Conservatism.

\section{INTRODUÇÃO}

O artigo tem o objetivo de analisar as afinidades e contradições entre as teorias do "destino manifesto" e da "experimentação democrática" na história política americana, confrontando-as no plano geral, mas delineando ao final do artigo as evidências do destino manifesto no governo Trump. Essa contenda, na verdade, é elaborada mais sob um modelo de transversalidade do que propriamente de conflito, uma vez que os fundamentos contidos nas duas hipóteses convivem sob as mais diversas interpretações a caminho da construção da Teoria da América, sempre inacabada.

Quanto à metodologia, a opção por um texto ensaístico permitiu buscar informações também em fontes secundárias mais próximas dos acontecimentos históricos originais que serviram ao propósito de contemporizar os argumentos. O artigo explora resultados eleitorais presidenciais auferidos por meio de fontes secundárias (Pew Research Center, Valor Econômico, CNN) e discorre sobre os arranjos políticos com apoio da bibliografia especializada.

Na primeira seção, buscou-se identificar as diferenças entre os dois princípios civilizatórios da América e sua evolução temporal. Na segunda seção, a pesquisa bibliográfica foi conduzida de tal modo a explicar como a história da política americana foi sendo descrita sob a forma de ciclos conservadores e progressistas, que refletem as duas vertentes. Considerou-se a origem e as diversas interpretações sobre o significado da teoria do destino manifesto ao longo desses ciclos. Na última seção, a ideologia do destino manifesto é dissecada em termos de sua concretização no governo de Donald Trump e especula-se quanto a sua continuidade.

Para caminharmos na direção das duas teorias, precisamos compreender o contexto sociopolítico dos EUA antes da década de 1840, o qual é descrito magnificamente por Alexis de Tocqueville em Democracy in America (1835). Desde que chegou em 1831 na cidade de Nova Iorque junto com Gustave Beaumont, ambos passaram meses nos Estados Unidos e Canadá, fazendo apontamentos sobre as características da sociedade americana, abrangendo a sua economia e o seu sistema político até então com traços únicos no mundo.

O aspecto da democracia que capturou de forma mais contundente a atenção do francês foi a complexa elaboração do princípio de igualdade, que, desde a implantação das colônias, continha todas as características de um fato providencial. Como aristocrata francês, Tocqueville preocupouse em analisar prováveis ajustes entre a liberdade individual, potencializada pelos fundamentos do Iluminismo na França, e a igualdade, fortalecida na moderna democracia americana pelos ideais da Constituição após a revolução da independência (TOCQUEVILLE, 2005 [1835], p. 18-20). 
Sua permanência nos Estados Unidos coincidiu com o governo do presidente Andrew Jackson, uma época em que os partidos políticos estavam num processo de transformação radical, deixando de ser pequenas organizações dominadas por elites locais ou comissões eleitorais para se tornar corporações de massa impulsionadas a eleger funcionários nos níveis local, regional e nacional. Tocqueville sabia que, nos Estados Unidos, desde a vinda dos colonos ingleses no século XVII, a democracia constituía um poderoso símbolo nacional, sendo sua aceitação equivalente a um teste de lealdade e patriotismo do cidadão.

Voltando dois séculos antes, após a incipiente tentativa de colonização autoritária e centralizadora iniciada em Jamestown - Virgínia, o experimento democrático veio com o assentamento na Nova Inglaterra, fundado por dois grupos religiosos diferentes: os peregrinos, que queriam sair da Igreja da Inglaterra, e os puritanos, que queriam reformá-la.

O quadro que Tocqueville (2005, p. 247-260) diagnosticou no século XIX sobre a fascinante democracia americana era primordialmente um reflexo da luta pela liberdade política, religiosa e econômica que vinha desde a agitação travada inicialmente na Inglaterra. $\mathrm{O}$ "individualismo congregacionalista” dos peregrinos e puritanos do século XVII foram importantes fatores do liberalismo que contribuíram para o desenvolvimento da democracia americana.

Esse panorama ganhou excepcional fascínio por outro fato histórico significativo: o alargamento das fronteiras das 13 colônias em direção ao Oeste. Sem as amarras do velho continente, o fortalecimento da ideia da igualdade pode finalmente ser difundido no século XIX, uma vez que a riqueza deveria ser para todos. Tal combinação não poderia ser evidenciada na Inglaterra, cujo governo, embora liberal, não se podia dizer que era plenamente democrático. Mesmo que os ingleses tenham se orgulhado por viverem em uma nação livre, acostumada à eleição de um corpo legislativo que limitava os poderes da monarquia e desfrutassem de um Judiciário cada vez mais independente, a estrutura jurídica e social fundamentava-se apenas em certos direitos dos sujeitos mantidos por leis escritas. Além disso, não havia terras que pudessem ser apropriadas por indivíduos, pois grande parte estava nas mãos das corporações religiosas, da nobreza ou da nova burguesia em processo de expansão de suas fábricas.

Até mesmo os mais céticos poderiam ficar impressionados com a capacidade da força que a América poderia extrair dos fundamentos da democracia. Esse fio condutor, entretanto, foi sofrendo modificações a partir da década seguinte e, nesse processo, surgiu a Teoria da América, que, entre outras coisas, serviu como pretexto para a interpretação do avanço territorial até o Pacífico e de seu acúmulo simbólico.

\section{A TEORIA DA AMÉRICA: EXPERIMENTO DEMOCRÁTICO OU DESTINO MANIFESTO?}


Imaginemos um tapete de muitos desenhos, trançado com dois fios de cores diferentes e entrelaçados um no outro. Essa é a metáfora que Schlesinger Junior (1992) utiliza para sintetizar como o significado da América vem sendo decifrado pela sociedade americana, desde que os peregrinos do Mayflower desembarcaram em Plymouth, no distante ano de 1620.

O primeiro fio foi tecendo a ideia de uma história providencial que considerava todas as comunidades seculares finitas e problemáticas a partir do princípio de que floresciam e entravam em decadência, sendo este o pensamento dominante nas 13 colônias ao tempo de sua independência, em 1776. Isto não exclui o fato de que autores como Nancy L. Rosenblum (2000, p. 438) se refira aos Estados Unidos como uma "nação protestante" ou "fundada em princípios protestantes". Por outro lado, Holmes (2006, p. 13), embora enfatize sua herança calvinista, adverte que as chamas do calvinismo que haviam impulsionado os peregrinos à conquista da América haviam baixado após a independência. A ideia do inferno e o pecado original não haviam sido abandonados, mas a tradição reformada sobre esses dogmas era mais secularizada. Havia o entendimento de que os EUA passavam por um tempo de provação na busca pelos ideais de liberdade que deveriam nortear a nova nação independente.

Essa insegurança a respeito do empreendimento americano era alimentada por estimativas europeias sobre o futuro dos EUA, “uma vez que políticos influentes do velho mundo possuíam uma visão degenerativa da América e não a visão idílica da felicidade lockeana" 3 (SCHLESINGER JUNIOR, 1992, p. 8). No começo da república, esta era a temática predominante na vida política americana, ou seja, a ideia dos EUA como uma experiência carregada de riscos e problemas que desafiavam a história.

Retomando o momento da visita de Tocqueville à América, percebemos que esta ocorre em um momento de confirmação do êxito dessa experiência americana. Tendo constatado a importância do caráter nacional para a liberdade existente no país, e embora tenha dado crédito aos religiosos puritanos pela modelagem desse caráter, não passava pela mente de Tocqueville analisar esse contexto por um ângulo escatológico ou messiânico, tese que seria enfatizada na sociedade americana somente alguns anos depois. Nas sociedades aristocráticas, como a inglesa ou francesa, onde coexistiam vários níveis de desigualdade separando nobres, burguesia e clero, as diferenças não chocavam tanto, mas, na democracia americana, as distinções mais insignificantes se tornaram insuportáveis. O historiador Ekirch Junior (1965) destaca que Tocqueville revelava em seus livros os princípios aristocráticos liberais europeus nos quais acreditava, mas teria confessado que, na América, conseguia perceber a imagem da própria democracia, “com suas inclinações, seu caráter,

\footnotetext{
3 John Locke foi um importante filósofo inglês, um dos líderes da doutrina filosófica do empirismo e um dos ideólogos do liberalismo e do iluminismo. Por ocasião das guerras religiosas na Europa, formulou o seu raciocínio clássico para a tolerância religiosa: (1) Os juízes da terra, o estado em particular e os seres humanos em geral, não podem avaliar as afirmações de verdade de pontos de vista divergentes; (2) Aplicar uma única "verdadeira religião" não teria o efeito desejado, a crença não pode ser compelida pela violência; (3) A coerção da uniformidade religiosa levaria a mais distúrbios sociais do que permitir a diversidade.

Fonte: McGrath, Alister (1998, p. 214-215).
} 
seus preconceitos e suas paixões, a fim de aprender o que temos a temer ou a esperar de seu progresso" (EKIRCH JUNIOR, 1965, p. 112).

Essa obstinação pela igualdade, teria proporcionado a Tocqueville constatar o princípio do poder da maioria, manifestada com maior evidência no controle que o povo exercia sobre o governo e a imprensa. Nas palavras de Ekirch Junior "a insistência democrática sobre a igualdade e o ódio ao privilégio causaram ênfase sobre a uniformidade" (EKIRCH JUNIOR, 1965, p. 114). O indivíduo era coagido pelo sistema legislativo e pela influência da opinião pública. Essa característica estimulava um tipo de associação comunitária ainda ausente na Europa, mas que, nos EUA, potencializava o poder de barganha da população com as autoridades. Sobre isso, Rodrigo Constantino manifestou o seguinte ponto de vista:

Entre as observações que [Tocqueville] fez sobre o país, consta a extraordinária força das associações voluntárias no dia a dia da vida americana, como uma força social muito mais potente e extensiva que o Estado. Se os franceses se voltavam para o Estado, e os ingleses para a aristocracia, os americanos formavam livres associações uns com os outros quando precisavam ou demandavam alguma coisa. Assim praticavam o autogoverno. Não dependiam do governo, mas se organizavam para alcançar os próprios objetivos. (CONSTANTINO, 2013)

Esse cenário delimitado por Constantino coincide com o que de costume Tocqueville constatou na sua visita aos EUA e ocorreu em um momento de consolidação da teoria do experimento democrático, mas a verdade é que um segundo fio desse tapete já havia começado a ser trançado assim que a missão dos fundadores foi dada como cumprida em 1776. Embora não tenha se tornado predominante até 1840, esse fio permitiu o surgimento de um fervor patriótico que, muito além dos limites da comunidade evangélica, subscrevia os americanos como um povo eleito, incumbido de uma missão divina. Assim, o "Reino de Deus era tido ao mesmo tempo como iminente no tempo e imanente na América” (SCHLESINGER JUNIOR, 1992, p. 16).

A independência deu novo status à teoria da América, que passou a ser vista por alguns formadores de opinião e autoridades eclesiásticas como "nação eleita”. Um dos mais famosos líderes religiosos da época, o Rev. Josiah Strong, defendia que os hebreus, gregos e romanos, vistos como fonte de inspiração pelos fundadores, teriam desenvolvido separadamente as qualidades espirituais, intelectuais e físicas do homem para desembocar em uma só e suprema civilização na nova era. Essa raça única, seria a anglo-saxônica, escolhida por Deus para preparar o caminho para a realização de seu reino na terra (SCHLESINGER JUNIOR, 1992, p. 17).

Pois bem, nos anos posteriores ao retorno de Tocqueville à França, figuras como o Rev. Alexander Blackburn, Albert Beveridge, Woodrow Wilson e John Foster Dulles retomaram essa interpretação. Desenvolveu-se a crença na nação idealista e na sua eleição para conduzir a regeneração do mundo, realizar o seu destino e salvar a humanidade, o que, de certo modo, configurava um deslocamento em relação às observações do aristocrata francês. 
Uma das explicações é que, quando a consciência histórica americana se diluiu, a esperança messiânica teria começado a ocupar o vácuo, mas, no decorrer das décadas que se seguiram à independência, o cristianismo ganhou feição liberal, expurgando doutrinas fundamentais como o pecado original e o caminho teria ficado aberto à crença na retidão e na superioridade dos Estados Unidos.

De fato, a "experiência democrática" foi cedendo lugar ao "destino manifesto" como argumento da vida nacional. Como afirmou Ekirch Junior (1965, p. 104), contrastando com a época da Revolução americana quando o cristianismo corria o risco de ser secularizado pelo novo nacionalismo americano, nos anos seguintes à revolução até a época da visita de Alexis de Tocqueville, parecia haver alguma perspectiva de que o protestantismo evangélico teria domínio sobre a nova ordem democrática, mas não havia aspectos materializadores que evidenciassem o protagonismo desse fenômeno.

O autor prossegue dizendo que, na democracia desse período médio americano, desde 1829 sob o governo de Andrew Jackson, havia equilíbrio entre a indústria e a agricultura, assim como entre a vontade da maioria e os direitos das minorias. O nacionalismo típico do tempo dos fundadores ainda teimava em dar as caras, mas isso era restrito aos estados sulinos. A democracia, embora houvesse perigo de que se tornasse uma fé religiosa das massas, era modelada por várias forças compostas da democracia jacksoniana, especialmente o desenvolvimento da ciência e do industrialismo (EKIRCH JUNIOR, 1965, p. 105-6).

O conflito entre realismo e messianismo, experimento e destino manifesto, ocorreria somente após 1840, quando a linha divisória ficou então mais explicitamente demarcada. Seria natural supor que, a partir desse ponto, pudéssemos fazer a correlação da Teoria da América com a origem dos partidos Democrata e Republicano. Essa análise seria simplista, até porque os dois partidos, na forma como existem hoje, são frutos de cisões e não estiveram ocupando sempre as mesmas posições semânticas. De qualquer modo, antes da bipolaridade atual, devemos considerar que a história política americana foi conduzida pelos partidos Federalista e Democrata-republicano, sem falar no Whig4, de inspiração inglesa.

Para um diagnóstico que identifique a natureza ideológica dos partidos e suas prováveis relações com a teoria da América, precisamos analisar os hipotéticos ciclos da democracia americana para tentar relacionar esses ciclos aos dois polos (messianismo ou realismo) e somente depois compreender como isso tem relação com os partidos e o governo de Donald Trump. A combinação desses fatores pode ou não apresentar coincidências com as ideologias partidárias.

4 O Partido Whig foi fundado por Henry Clay, durante a era da "democracia Jacksoniana", entre 1833 e 1834. Formou-se em oposição às políticas do presidente Andrew Jackson do Partido Democrata, tendo sido dispersado em 1856 e posteriormente absorvido pelo Partido Republicano. A ideologia política do partido baseava-se no protecionismo e na modernização, tendo recebido essa denominação em analogia aos Whigs britânicos, que se opuseram ao poder real durante a Restauração inglesa. Fonte: Dicionario.sensagent.com 


\section{OS CICLOS HISTÓRICOS DA DEMOCRACIA AMERICANA E OS VESTÍGIOS DO DESTINO MANIFESTO}

A ideia de alternância ou de fluxo e refluxo na história política americana aparece com certa frequência em vários autores. Normalmente oscilam entre conservantismo e inovação, conforme notou o próprio Schlesinger Junior (1992, p. 25). Ambos os princípios disputam a posse do mundo, pois, enquanto a inovação pressiona sempre querendo avançar, o conservantismo retrai as conquistas. Quando Ralph W. Emerson escreveu Essays: First Series (1847), da qual citamos o ensaio "Circles", o autor afirmava que "somos reformadores na primavera e no verão, no outono e no inverno, ficamos com o velho”. E prossegue: “a inovação é a energia saliente. O conservantismo, a pausa no último movimento".

Talvez não haja maior defensor da existência dos ciclos na política americana do que Arthur Schlesinger Senior, cuja primeira versão de seu argumento Tides of American Politics, publicada na Yale Review em 1939, e sua revisão em Paths to the present (1949) apontavam para uma interpretação adaptada desse fenômeno, pois trabalhava a ideia de uma oscilação entre conservantismo e liberalismo. Seu filho, Arthur Schlesinger Junior, na obra Os ciclos da história americana (1982), confirma que seu pai prescreveu no ensaio de 1949 o seu quebra-cabeça: defendia que a política americana ocorria em meio a um rodízio entre dois períodos definidos: preocupação com os "direitos das minorias" separados por intervalos de "preocupação com os erros da maioria" (SCHLESINGER Jr., 1992, p. 26-27).

Na teoria de Schlesinger Senior, os seus três primeiros ciclos correspondiam aos mesmos períodos de Henry Adams e cobrem os anos de 1776 a 1812, no qual alternaram-se ideias liberais e conservadoras. Nesse período, os fundadores da nova república assumiram a presidência a partir de George Washington (1789-1797), John Adams (1797-1801) e Thomas Jefferson (1801-1809).

Schlesinger Junior (1992, p. 26) afirma que, após esses três ciclos de 12 anos, seguiu-se o período conservador da retirada jeffersoniana, posterior à guerra de 1812, com James Madison (1809-1817), James Monroe (1817-1825) e John Quincy Adams (1825-1829). A partir desse ciclo, tendo como fontes outros historiadores e analistas políticos, foi possível cruzar os dados da teoria de Schlesinger Senior com as ideologias predominantes do destino manifesto e da experimentação democrática.

A presidência de Andrew Jackson (1829-1837) coincidiu com o revezamento conservadorliberal de Schlesinger que ele chamou de "idade democratizadora de Jackson", que se estende até 1841. Nesse contexto, surgiu, em 1828, o Partido Democrata. Segundo Stuart Brown (1954), a sua fundação está relacionada à cisão ocorrida no antigo partido Democrata-republicano, o segundo partido criado nos EUA em 1792 por Thomas Jefferson e James Madison. Quando chega ao poder em 180o, domina a cena política de 1801 a 1825, mas o historiador confirma que divergências 
internas originaram duas facções: o movimento Jacksoniano (resultando no Partido Democrata) e o Partido Nacional Republicano, sucedido pelo Partido Whig (BROWN, 1954).

Ao jornalista John O'Sullivan, credita-se a utilização do termo "destino manifesto" em um artigo publicado pela revista Democratic Review, de Nova York, em 1845, em meio ao novo ciclo conservador protagonizado pelos escravocratas. Segundo Linda Hudson (2001), o verdadeiro autor do artigo teria sido o jornalista e expansionista Jane Cazneau. O texto intitulado Anexação descrevia em termos retóricos que os americanos estariam destinados a construir uma grande nação, por vontade de Deus: “... e essa reinvindicação nos é dada pelo direito do nosso Destino Manifesto de nos expandir e possuir todo o continente que a Providência nos deu para o desenvolvimento da grande experiência da Liberdade”. Nesse contexto, aproveitando a guerra contra o México, o termo seria utilizado pelos democratas para justificar a anexação do Texas naquele mesmo ano.

O destino manifesto não foi uma teorização aceita de forma incontestável, pois havia críticas internas, especialmente na questão da escravidão, como atesta Frederick Merk (1995, p. 121-209). Quando analisou esse quadro, o autor constatou que a crença na eleição divina e a consequente expansão territorial não se constituía em prioridade nacional, chamando a atenção para o fato de que, em 1843, John Quincy Adams, grande estimulador inicial da ideia, flexibilizou sua opinião deixando de apoiar o expansionismo porque isso envolveria um prolongamento também da escravidão para o Oeste, através do Texas (MERK, 1995, p. 215-216).

A despeito dessas oscilações quanto à unanimidade da teoria do destino manifesto e das diferenças quanto aos objetivos e efeitos da política expansionista, o movimento da disseminação colonizadora nos Estados Unidos em direção ao Oeste e Sul acarretava, ainda que parcialmente, a justificativa moral da ideologia do destino manifesto.

A crescente dominação do governo nacional pelos escravocratas, entre 1841 e 1861, eclodiram as agitações políticas do novo período liberal, que seguiu entre 1861 e 1869, com a abolição da escravatura e o poslúdio da guerra civil entre confederados do Sul e os federados da União. James Davidson (2016) descreve como Abraham Lincoln (1861-1865), do partido Republicano União Nacional, liderou o movimento que impediu a autonomia política dos estados do sul e consolidou a Federação.

A guerra civil destroçou a nação, como advertira Lincoln, porque 250 anos de escravidão não podiam ser apagados facilmente. A Reconstrução foi um esforço corajoso de subverter esses anos de desigualdade. Mais um século se passaria até que a marcha para igualdade ressurgisse. (DAVIDSON, 2012, p. 166-167)

Em 1866, o presidente Andrew Johnson, que substituiu Lincoln, rompeu com os republicanos e aliou-se com o Partido Democrata, que se opunha à igualdade entre brancos e afroamericanos e à abolição do trabalho escravo equilibrando a balança política entre Norte e Sul. Seguiu-se um longo período conservador entre 1869 e 1901, no qual o destino manifesto concretizouse também por meio de um discurso de exclusão étnico-racial. Segundo Castel (1979), os estados do 
sul retomaram as ações restritivas aos direitos dos negros e aprovaram os Black Codes para privar os negros libertos dos seus direitos civis. As tensões entre os republicanos no Congresso e os legisladores sulistas apoiados por Johnson colocou em xeque a estabilização alcançada com a reunificação liderada por Lincoln. Enquanto o Sul elegia governadores democratas, uma série de presidentes do partido Republicano ocuparam o poder até 1901, com exceção de Glover Cleveland.

Durante esse período, consolidou-se a expansão para o Oeste e a virtude civilizatória foi invocada várias vezes para justificar o fenômeno. O historiador William Weeks (1997, p. 14-98) expôs a existência de três propósitos utilizados pelos defensores do destino manifesto: a virtude das instituições e dos cidadãos dos Estados Unidos, a missão de estender essas instituições refazendo o mundo à sua imagem e a decisão de Deus de consagrar aos EUA à execução dessa missão. Ele argumenta em termos de um governo central que, após a adoção da Constituição, conjugou a necessidade de expansão com um nacionalismo americano messiânico. Para tal, uma ação diplomática agressiva teria sido acionada por sucessivos presidentes desde a aquisição da Louisiana e da Flórida, passando pela Guerra do México até a anexação do Texas, tendo como pano de fundo as relações com a Grã-Bretanha, França e Espanha.

Segundo o sociólogo Demétrio Magnoli (1997), essa expansão apoiou-se em quatro pilares: noções de segurança; predestinação geográfica; difusão da liberdade e lei de gravitação políticogeográfica. O primeiro paradigma revela o destino manifesto como indutor para a expansão do território americano, uma vez que a suposta invasão de terras americanas, justificaria a defesa dos seus territórios. Magnoli (1997, p. 20) constata que a anexação da Louisiana, mediante negociação com Napoleão em 1803, teria sido o indício original e concreto dessa política. Isso ocorreu em um momento político no qual os democratas-republicanos, sob a liderança do presidente Thomas Jefferson, defendiam menos centralização política e maior autonomia aos estados e lideranças locais. Como o porto de New Orleans próximo à foz do rio era indispensável para a economia americana, o governo percebeu que a posse da região por Napoleão seria uma ameaça aos direitos de comércio e à segurança do interior. Os EUA compraram a Louisiana por USS 15 milhões.

O segundo paradigma defendido por Magnoli (1997, p. 21-22) era baseado no fato de que a fronteira de um país deve ser instaurada por um limite geográfico. No caso dos EUA, esse limite, que era inicialmente os Montes Apalaches, teria avançado até o Oceano Pacífico. A anexação da Flórida (1819), ocorrida no governo conservador de James Monroe (1817-1825), e do Texas, no pico do escravismo, são os exemplos indutores.

Em relação ao terceiro fator, Magnoli (1997, p. 23) atribui à extensão das instituições americanas para povos que não a haviam escolhido. O destino manifesto teria o objetivo de adquirir as feições de um altruísmo civilizatório, sustentando a ideia de ação regeneradora destinada a conduzir os outros povos para a Nova Jerusalém. Essa ideia de difusão de liberdade foi utilizada pela primeira vez pelo presidente Andrew Jackson para justificar a inclusão do Texas na União e 
posteriormente para a tomada dos estados da Califórnia, Novo México, Arizona, Nevada, Utah, partes do Colorado, Kansas e Oklahoma na Guerra contra o México que durou de 1846 à 1848.

Finalmente, o quarto paradigma caracterizou-se pelo direito que os EUA julgaram ter sobre as ilhas ou terras pertencentes ao Estado americano, localizadas fora do continente. Segundo Magnoli (1997, p. 24), com a incorporação desse novo fator, por meio da teoria do destino manifesto, justificava-se as anexações do Alasca, Havaí, Filipinas e Porto Rico.

Num momento posterior, os dois últimos paradigmas do destino manifesto, revestidos ideologicamente sob vários aspectos, foram utilizados como alegação para ingerência em outros países durante a chamada "Guerra Fria" (1945-1991) e ainda pudemos perceber que esse discurso continua sendo utilizado pelos EUA em recentes invasões no Oriente Médio, a partir do governo Bush. Essa nova face da teoria não considera o domínio territorial como meta e sim o domínio econômico da região, especialmente nas questões da defesa da liberdade.

Com Theodore Roosevelt, teve início em 1901 a era progressista, que se estendeu até 1919. Além de Roosevelt, do partido Republicano, incluíram-se nesse ciclo os presidentes: Wiliam Taft (1909-1913), também do partido Republicano, e o democrata Woodrow Wilson (1913-1921). O ciclo da Restauração Republicana, segundo Schlesinger Junior (1992, p. 25), teve início em 1919 e se estendeu até 1931. Ainda vivendo as tensões e consequências do crack da Bolsa de Valores de 1929, sucedeu-se nova onda liberal: a era do New Deal (1931-1947), iniciada ainda no governo Hoover, cujos tentáculos atravessaram também a II Guerra Mundial. Mesmo considerando a assertiva dessa nova onda liberal a partir do New Deal, é necessário esclarecer que isso não representaria um retorno puro e simples às temáticas do passado. Ao contrário, períodos conservadores ou liberais sempre potencializaram releituras e produziram novos fatos políticos e sociais, mesmo que mantidos os padrões primários essenciais.

As noções de Liberalismo e Conservadorismo, que estão embasando nossa análise sobre o destino manifesto, sofrem uma releitura nesse período. A pesquisadora Camila Vidal, em recente artigo na Revista Latino-americana de Relações Internacionais, assegura que

a concepção de "Liberalismo" emerge no meio político para lidar com questões práticas e está associada diretamente às políticas do New Deal, enquanto o "Conservadorismo" é construído no meio acadêmico com aporte do empresariado e apoio de lideranças evangélicas na tentativa de articular uma frente oposta à essas mesmas políticas. (VIDAL, 2019)

A ressignificação do liberalismo, nos termos de Roosevelt, seria ancorada em 1936 pelas teorias de Keynes, mas, como força motriz da nova realidade político-econômica dos EUA, encapsulava a ideia de que os princípios liberais do Iluminismo não poderiam dar conta das novas demandas americanas após a I Guerra Mundial e o crack de 1929, conjugadas em um ambiente de monopólios e empresas interferindo nas liberdades individuais. Para Alan Lawson, o mentor do New Deal, Franklin Roosevelt, teria batizado o novo liberalismo americano sob uma bandeira protetora 
do Estado em contraponto às referencias europeias do laissez-faire vigentes até o início do século XX. Nesse sentido, esta seria a conjuntura culminante da tradição progressista americana e agiria como precursora da Great Society de Lyndon Johnson nos anos 1960 (LAWSON, 2006).

Em 1934, Franklin Roosevelt substituiu, na América Latina, a política “do porrete” pela da Good Neighbourhood (boa vizinhança). Nos anos seguintes, Maurice Lemoine opina que, quando os Estados Unidos conseguem organizar regimes autoritários estáveis, ancorados no poderio militar local dos países, garantem um toque sutil à teoria do destino manifesto, uma vez que a boa vizinhança seria materializada no apoio aos ditadores Rafael Leónidas Trujillo (República Dominicana), Juan Vicente Gómez (Venezuela), Jorge Ubico (Guatemala), Tiburcio Carias (Honduras), Fulgencio Batista (Cuba) e à dinastia Somoza na Nicarágua (LEMOINE, 2003).

Quando o novo período conservador se iniciou em 1947, posteriormente, em Paths to the Present (1949), Schlesinger Senior previu que esse recuo do liberalismo se encerraria em 1962. Com base nas predições do historiador americano, a nova era liberal deveria durar até 1978 (SCHLESINGER JUNIOR, 1992: 26-27)5.

A era liberal projetada para 1962-1978 incluiria dois presidentes democratas que Schlesinger Senior testemunhou antes de sua morte: John Kennedy (1961-1963) e Lyndon Johnson (1963-1969). Os dois presidentes republicanos, Richard Nixon (1969-1974) e Gerald Ford (1974-1977), que os sucederam, provavelmente não poderiam ser classificados como liberais, mas, mesmo assim, Irwin Gellman (2012), que relatou a carreira de Nixon no Congresso, chegou a dar uma pista de seu "liberalismo político" na condução da política internacional americana quando afirmou que "ele foi notável entre seus pares no Congresso, uma história de sucesso em uma era conturbada, que conduziu um curso anticomunista sensato contra o excesso de McCarthy" (GELLMAN, 2012, p. 460). Quanto à Gerald Ford, ao contrário, teria pavimentado a pista do destino manifesto para períodos posteriores por conta de dois nomes que compuseram seu staff: Donald Rumsfeld, chefe de Gabinete da Presidência e posteriormente para o Departamento de Defesa, e Richard Cheney, que o sucedeu no Gabinete presidencial. Além disso, George Bush, presidente do Partido Republicano, seria escolhido para a direção-geral da CIA (ARRAES, 2006).

Se esse ciclo político não pode ser facilmente identificado como conservador ou liberal, na ótica conservadora-cristã não havia dúvidas. A direita religiosa, formada por católicos, judeus ortodoxos, protestantes, pentecostais, evangélicos e organizações como Moral Majority e Christian Coalition, cuidavam de transformar a agenda americana nas décadas de 1960 e 1970 como um espelho do destino manifesto, agora alçado a um novo status, abordando temas como moralidade, religião, sexualidade e família (ABERBACH e PEELE, 2011). Critchlow (2007) confirma que, sustentadas pelas megachurches (superigrejas), a direita religiosa alcançou o seu ápice com o

5 Os dados da alternância conservantismo-liberalismo referem-se ao período 1776-1978 e foram retirados do livro "Os ciclos da história americana" (1982), de Arthur Schlesinger Junior, baseados na teoria revisada de seu pai, Arthur Meier Schlesinger em Paths to the present, de 1949. 
surgimento da Igreja Eletrônica, movimento que incluía redes de TV e rádio religiosas em escala global. O conservadorismo bebia das contribuições da Ford Foundation, Lilly Endowment, Scaife Foundation e empresas como: General Motors, US Steel, Mobil, Standard Oil (CRITCHLOW, 2007, p. 40-71). Organizações lobbystas situadas em Washington alavancaram lideranças como os pastores Jerry Falwell e Pat Robertson. Seus objetivos estavam atrelados a mobilizar ativistas morais no Congresso contra as tendencias liberais de defesa do "bem-estar social" conforme atestam Schneider (2009) e Diamond (1995).

Quando lideranças evangélicas, como Jerry Falwell e Pat Robertson, movem-se em direção às instituições políticas, possibilitam o acionamento de engrenagens morais e religiosas que cruzam os interesses da agenda política nacional com os princípios declaratórios do destino manifesto, invocam novamente a proteção de Deus aos EUA e impulsionam profundas mudanças no Partido Republicano. Como a religião ganha escala no movimento conservador e no partido, a ascensão de Ronald Reagan, George W. Bush e Donald Trump podem ser examinadas como a continuidade desse processo.

O embaraço continuaria com o suposto período do novo ciclo conservador. Se tomarmos o ano de 1978 como o início dessa nova etapa, poderíamos projetar o novo quartel conservador para até o ano de 1993, quando tem início o governo Clinton. Assim teríamos que incluir o democrata Jimmy Carter (1977-1981) nesse novo ciclo ao lado dos republicanos Ronald Reagan (1981-1989) e George H. W. Bush (1989-1993). Nesse ponto, as dificuldades seriam menores, porque não encontramos resistência quanto a inclusão de Carter nesse período conservador, uma vez que isso tem sido corroborado pela maioria dos analistas políticos contemporâneos.

O período liberal seguinte seria circunscrito à temporada do democrata Bill Clinton (19932001). A partir desse presidente, se ajustarmos hipoteticamente os ciclos para um período máximo de oito anos e compararmos com os períodos dos partidos que governaram a Casa Branca, verificamos que estão superpostos. De fato, com George Bush (2001-2009) poderíamos traçar nova rota conservadora republicana, na qual o destino manifesto se exteriora sob a velha presunção protetiva da democracia, advogada por Magnoli (1997). Isso fica demonstrado na confirmação da soberania militar americana na cena política do Oriente Médio, especialmente com a Guerra do Golfo. Entre 2009 e 2017, presenciamos o governo democrata de Barack Obama que teria encapsulado novo período liberal, relativizando a relação com os imigrantes, ampliando a cobertura médica aos americanos e flexibilizando as tensões com os regimes autoritários do Oriente Médio. Finalmente nos detemos na eleição do republicano Donald Trump sob a bandeira do "America First”. Nesse caso, poderíamos identificar o início de nova temporada conservadora em 2017, da qual se esperava que permanecesse até 2024, caso fosse mantida a sua reeleição.

Quando os ciclos conservadores prevaleciam, normalmente o discurso do destino manifesto se fazia mais presente, contrapondo-se à experiencia democrática anterior e ganhava escalas ou protagonismos à medida que se ressignificava como teoria civilizatória dos EUA. 


\section{PISTAS DO PASSADO REVELAM O FUTURO: O TRUMPISMO E A VISÃO MÍSTICA DA AMÉRICA SOBREVIVEM?}

A visão da América, que está na gênese da teoria do destino manifesto, deve ser observada no seu contexto religioso para somente depois permitir altercações no campo político-econômico e das relações internacionais que possibilitem avaliar sua dimensão em governos. De início, a liberdade política e econômica asseguradas durante a Revolução americana foi acompanhada em diversos estados pela separação da Igreja e do Estado e a propagação da liberdade religiosa. Segundo Ekirch Junior (1965, p. 51-52), esse quadro trouxe algumas consequências: em primeiro lugar, a perda da influência da Igreja Anglicana, especialmente nos estados do sul, pela sua ligação natural com a matriz britânica. Em segundo lugar, a Igreja Congregacional na Nova Inglaterra foi coagida a rever, na maioria dos membros da federação daquela região, o seu status de "igreja do Estado", conquistado em detrimento das demais seitas. Em terceiro lugar, o crescimento dos batistas no Sul e dos presbiterianos nas fronteiras do Oeste, além da imigração cada vez maior de católicos, exerciam forte pressão sobre a pouca tolerância à individualidade religiosa que vinha dos tempos coloniais e que tivera que ser reparada a fim de estabelecer de fato o direito à livre prática da religião.

Ao acelerar a separação da Igreja e do Estado, a revolução também estimulou um pensamento mais plural, que não somente questionava a autoridade das igrejas Congregacional e Anglicana, como reinterpretava os discursos bíblicos segundo uma proposta que unia a visão da "Nova Jerusalém”, com os propósitos divinos para a América e a consequente expansão territorial para o Oeste. Mesmo assim, o destino manifesto como uma das expressões da democracia americana, na sua vertente religiosa, não tinha sido exercida plenamente senão como um princípio de mérito teórico, especialmente depois da compra da Louisiana, em 1803.

Embora não faltasse o combustível religioso e certo grau de imperialismo nacional no conceito de destino manifesto, a partir de 1830, a expansão territorial era percebida como a opção para a maior liberdade econômica e política. Pode-se assim afirmar que o destino manifesto não é uma expressão do comportamento americano restrito ao campo da religião ou em oposição à teoria do experimento democrático, mas que, imbuído da ideologia de que a democracia estava destinada a tornar-se a filosofia política de todos os povos, encharcava-se de doses de patriotismo e humanitarismo civilizatório, o que ajudava a materializar a própria teoria do destino manifesto.

A resposta se o trumpismo estimulou novamente o fervor messiânico inerente à teoria do destino manifesto pode ser mais bem compreendida se observarmos o discurso de posse de Donald Trump $^{6}$. Aspectos xenófobos e populistas presentes no texto poderiam significar que as velhas políticas imperialistas fariam parte da agenda do novo mandatário. Além de afirmar que "nós

\footnotetext{
${ }^{6}$ Informações extraídas do discurso de posse de Donald Trump em 20 de janeiro 2017, publicado pela
} Embaixada e Consulados dos EUA no Brasil. 
seremos protegidos por Deus" e "a Bíblia nos diz: Quão bom e agradável é quando o povo de Deus vive junto em unidade" parecendo reforçar o excepcionalismo americano em sua relação com o "Criador", usou também uma expressão que lembra enunciados do Big Stick (uso da força): "vamos erradicar o terrorismo da face da terra". Manifestou o desejo de construir um muro para isolar as fronteiras mexicano-americanas e desmontar os programas sociais criados por Obama. Durante o seu mandato, a partir do episódio da tentativa de apoiar a troca da capital de Israel para Jerusalém, emite uma mensagem clara de que os americanos seriam um povo eleito para agirem como procuradores dos judeus, quem sabe, "precipitando o retorno de Jesus", a partir do conflito entre israelenses e estados muçulmanos. Seria assim possível afirmar que o trumpismo subiu o tom do caráter religioso do destino manifesto e, embora não tenha solapado inteiramente as doses seculares de patriotismo e de autorreferência dos EUA, quase sempre misturadas ao messianismo característico da teoria, impregnaram o discurso de Donald Trump de significativa magnitude religiosa.

Essa pista de republicanismo clássico não é uma novidade que tenha chegado com Donald Trump. Observando os vários presidentes americanos, muitos defenderam os ideais escatológicos do destino manifesto, como observou Carlos da Fonseca (2007)7.

Incontáveis alocuções presidenciais, ao longo de todo o século XX e agora no XXI, refletem esse sentimento. De puritanos como Kelvin Cooligde a católicos como John Kennedy e evangélicos como Jimmy Carter e George W. Bush; de beatos como Edgard Hoover e Dwight Eisenhower a céticos como Franklin Roosevelt e Lyndon Johnson: todos os presidentes norte-americanos desse período fizeram uso, em um momento ou outro, da rationale religiosa para explicar, justificar, legitimar ou simplesmente descrever o papel do país no mundo. (FONSECA, 2017)

Deixando de lado a vertente mística mais "pura”, do ponto de vista exclusivamente político, uma leitura menos crítica poderia indicar que Donald Trump não teria trazido nenhum novo paradigma político. Com base no discurso de posse e nas trajetórias dos vários presidentes identificados por Fonseca, seu governo representaria o retorno do ciclo conservador, centrado no interesse privado, nos princípios capitalistas puros e na crença da providência divina, reproduzindo os mesmos elementos caracterizadores de cada um dos ciclos anteriormente discutidos.

Schneider (2009) demonstra que o que apareceu foram novos porta-vozes com estratégias flexíveis ou até mais radicais, porém os instrumentos parecem ser os mesmos. Ele atesta que figuras como Rush Limbaugh e Newt Gingrich utilizariam veículos de comunicação como a Fox News e movimentos como o Tea Party para disseminar os princípios conservantistas. Nacionalistas isolacionistas, "paleoconservadores" e tradicionalistas disputam espaço com internacionalistas intervencionistas na agenda política do Partido Republicano e na ressignificação dos ideais conservadores (SCHNEIDER, 2009). O conservadorismo não advoga uma ideologia de mão única,

\footnotetext{
7 Artigo indexado pela SCIELO, em periódico ligado ao Instituto de Relações Internacionais, da PUC Rio, em 2007.
} 
antes funciona como um mosaico de visões, agendas políticas e proposições frequentemente não sinérgicas.

Em meio a essa pluralidade de correntes, devemos situar a crise que se instalou no Partido Republicano, percebida como inerente ao Trumpismo. Rafael Ioris (2021) lembra que a crise institucional do partido reflete as incertezas da sociedade norte-americana e que não teria começado com Trump. O pano de fundo dessas instabilidades não se estabeleceu somente por conta dos colapsos civilizatórios ligados aos radicais da direita ou desequilíbrios da economia americana, mas de um processo de cisão entre grupos sociais que se percebem como excludentes. Nesse quadro, segundo o autor, o Partido Republicano já não pode mais ser visto como sequestrado por Trump para esses fins, uma vez que grande parte de seus membros se alinha ao trumpismo por pragmatismo e não por convicção.

Anne Applebaum, da Escola de Estudos Internacionais Avançados da Johns Hopkins University, autora de Crepúsculo da Democracia: a atração sedutora do autoritarismo (2021), aprofunda essa percepção quando discute por que tantos líderes abandonaram a democracia liberal em favor de "cultos de homens fortes e regimes autocráticos". A rapidez com que os próceres do Partido Republicano cederam aos encantos de Trump estaria na razão de uma arquitetura construída das decepções com a democracia liberal, seja pela superficialidade da democracia moderna, seja pela mudança demográfica da sociedade como ocorre com o Reino Unido e EUA, ou ainda pelo suposto declínio da moral e dos valores que cercam os ex-adeptos do liberalismo.

A autora traça uma tipologia do Partido Republicano na era Trump dividindo-o em três grupos de associação. Primeiramente, os cabeças que se identificam com Donald Trump desde o início, admitindo uma compreensão apocalíptica da América que Trump parecia compartilhar. Há também aqueles que não nutrem sentimentos incrivelmente fortes por Trump, porém odeiam as concepções da esquerda e seus compromissos com políticas públicas, o que foi suficiente para admitir as pazes com ele. O terceiro grupo é mais complexo, pois seriam formados por aquelas lideranças que viram exatamente o que Donald Trump é, o odiaram, mas igualmente o aceitaram. Muitos que se enquadram nesse grupo atribuíram a Trump as características de um fanático religioso e xenófobo, mas tomaram pequenas decisões no campo de influência do partido, que, ao longo do tempo, criaram a expectativa de recuperar seus espaços culturais e oportunidades econômicas perdidas (APPEBAUM, 2021, p. 50-88).

Trump aproveitou-se da frustração desses segmentos em 2016 e continuou explorando-os ao longo do seu governo. O imigrante não branco e pobre foi o bode expiatório de uma campanha xenofóbica, chauvinista e divisionista, mas o discurso antissistêmico, no episódio do Capitólio, impôs aos republicanos o seu dilema: o partido retoma a narrativa institucionalista tradicional ou se consolida como o partido de extrema-direita populista mais importante no mundo.

Tendo em vista que a ideologia conservadora está impregnada de uma ação evangélica pública, torna-se necessário observar três aspectos. Em primeiro lugar, a alternância entre 
conservantismo e liberalismo, nos quais foram intercaladas as evidências do destino manifesto e da experimentação democrática, é um conceito defendido por Schlesinger Senior. Outros autores preferiram classificar os ciclos de forma diferente. Emerson fazia a distinção entre "conservantismo" e "inovação". O economista Albert Hirschman (1982) propôs outro modelo cíclico com uma alternância entre "interesse privado" e "atividade pública", como atesta o seu livro Shifting Involvements. Os cientistas políticos Herbert McClosky e John Zaller (2013), oferecem outra possibilidade em The American Ethos: uma disputa constante entre "valores capitalistas" e "valores democráticos". Associado ao capitalismo foram identificados: o preceito da propriedade privada, a maximização do lucro, o culto ao livre mercado e a sobrevivência do mais preparado. Como valores ligados à democracia, puderam ser nomeados: a igualdade, liberdade, responsabilidade social e bemestar social, tudo isso regulamentado pelo poder público e com alguma restrição ao lucro. Desse modo, embora capitalismo e democracia sejam faces da mesma moeda e tenham compartilhado no início da história americana os mesmos ideais de revolução contra a monarquia e a fé na liberdade individual, os dois credos apostaram em direções diferentes quando observamos o percurso dos ciclos, o que torna mais difícil elaborar uma visão didática do aparecimento das erupções religiosas ou políticas do destino manifesto.

Em segundo lugar, acompanhando ainda a trilha de Schlesinger Junior, a polaridade entre conservantismo e liberalismo poderia corresponder também ao conflito entre uma tradição "republicana" e outra "liberal", essa última entendida como livre empresa, paralela à formação do país. O próprio termo "republicano" revelava a virtude como "a alma das repúblicas livres e o temor pela corrupção do lucro egoísta e privado” (SCHLESINGER JUNIOR, 1992, p. 28-29). Assim, a dialética posterior entre democracia e capitalismo, ou objeto público e interesse privado, seriam na verdade reaparecimentos reflexivos dos tempos pós-independência, nos quais se discutia as vantagens da virtude e do comércio ou o debate sobre commonwealth e propriedade.

Por último, e não menos importante, ficamos com a alegação que Schlesinger Junior desenvolve sobre as divergências e as coincidências entre a concepção pragmática da América como um dentre muitos países da história, empenhado num arriscado experimento, e a visão mística dos EUA como um país do destino, escolhido por Deus para salvar a humanidade relapsa.

\footnotetext{
A equação público-privado e a equação experimento-destino sobrepõem-se em parte, em vez de coincidirem. Experimentalistas, como os dois Roosevelts, e predestinaristas, como Wilson, devotavam-se ao objetivo público enquanto homens práticos, como Eisenhower, e ideólogos, como Reagan, devotavam-se ao interesse privado. (SCHLESINGER JUNIOR, 1992, p. 29)
}

Feitas essas ressalvas, caberia então analisar se o novo impulso conservador, em geral, e o destino manifesto, em particular, seguem na era pós-Trump ou se uma temática liberal à moda Joe Biden poderá construir pontes híbridas entre a atividade pública e o interesse privado. 
Em recente artigo intitulado Understanding Trumpism: Politcs and Culture in an age of globalization, Mark S. Weiner (2020) analisou as perspectivas política, eleitoral e filosófica do governo de Donald Trump, notando um ponto comum entre elas que considera essencial para a sustentação de um governo democrático-liberal no futuro. Cada uma dessas dimensões implica uma identidade comunitária associada a um local territorialmente definido. Nas eleições de 2016, Trump teria explorado, a perda da confiança dos grupos "anti-elites" no governo constituído, especialmente no Meio-Oeste dos EUA, possibilitando a implantação de um discurso populista a serviço das demandas nativistas, cuja agenda política e geográfica coincidem. Ele assegura que os democratas perderam a eleição porque "esqueceram onde moram", assegurando que os movimentos populistas estão experimentando sucesso no mundo porque não cometem esse erro. Para o autor, os liberais terão que se confrontar com essa visão espacial que entrelaça comunidade e lugar quando a solidez das teorias universalistas está sendo deslocada pelo "senso de lugar cívico como paralelo ao senso de lugar geográfico e como uma pedra de toque de solidez em um mundo fluido". Weiner demonstra confiança na tradição liberal, que, em sua opinião, continua sendo a melhor para "alcançar a liberação humana" e continuar a construir intervenções na história. Ao mesmo tempo, questiona a capacidade de um liberalismo politizado desenvolver um compromisso autoconsciente baseado em regras de direito apoiadas em bases culturais e geográficas sólidas.

É preciso considerar esse ponto também no contexto das relações internacionais porque não são elas que determinam diretamente os ciclos ou realinhamentos dos EUA, pois estes são autogerados internamente. Ainda assim, podem dar pistas do redesenho do mapa político americano para os próximos anos. No caso de Trump, por exemplo, é evidente que ele preferiu agradar os exilados cubanos, restaurando várias restrições ao invés de ampliar o degelo anunciado por Obama em 2014. Nos episódios envolvendo as relações com a Rússia, foi bem menos combativo nos conflitos da Síria e Ucrânia. Ainda foi acusado de cumplicidade numa suposta interferência de Moscou na eleição de 2016. Com Trump, a retórica com a Coreia do Norte virou um campo minado com troca de ameaças entre governos, municiada de ofensas pessoais. No Oriente Médio, o trumpismo recolocou Israel como prioridade na agenda, declarou Jerusalém como sua capital e defendeu a transferência da Embaixada dos EUA para a cidade. Além disso, reacendeu o discurso nervoso com o Irã, rompendo o acordo nuclear assinado no governo Obama.

Estabelecido que o governo de Donald Trump rompeu o ciclo "liberal-democrata" do período Obama, podemos admitir que a partir de seu governo houve um renascimento do destino manifesto, na medida em que permitiu canalizar e potencializar o messianismo inerente à teoria, acrescido da possibilidade de que a parte da população americana comprometida com esses valores, além de reforçar a crença de que os EUA ainda são uma nação eleita, esteja se ocupando de criar expectativas de retorno ao status quo anterior do país. 


\section{CONSIDERAÇÕES FINAIS}

Vimos que Donald Trump tentou reiniciar um novo período conservador centrado em quase todos os valores tradicionais que foram aqui delimitados e definidos para o contexto americano em geral e o destino manifesto em particular: um sistema de crenças políticas que se caracteriza pelo respeito às tradições americanas, apoio aos valores judaico-cristãos, conservadorismo econômico, anticomunismo e defesa da cultura ocidental, reforçando a ideia da singularidade americana. A liberdade individual foi o ponto central de sua filosofia política. O conservantismo pode ser ainda identificado em vários outros campos: na área fiscal, não faltam defensores para o corte de impostos e, no campo dos direitos civis, vimos o crescimento fervoroso do apoio conservador à Segunda Emenda da Constituição dos Estados Unidos, que garante aos cidadãos americanos o direito de portarem armas de fogo de forma quase irrestrita.

Constatamos, entretanto, pontos nebulosos, não somente porque "conservador" é um termo "guarda-chuva", onde cabem várias interpretações com atributos que surgiram ou evoluíram para designar o que é conservadorismo, como também pelo desprezo dos governos de ocasião em ativar alguns dos traços tradicionais do conservantismo. É notório que o governo Trump esteve afinado com a maioria das facções conservadoras nos Estados Unidos que apoiaram uma política externa unilateral e pesados investimentos em apoio às forças armadas, contudo, desde o início do século XXI, conservadores americanos apoiavam políticas mais isolacionistas e protecionistas. Retiramos assim o ar de "novidade" ou de espetacularidade desse governo, pois todos esses pontos são retornáveis na história dos ciclos americanos, seja qual for a teoria que venhamos a abraçar.

O ciclo democrata dava demonstrações de esgotamento no último ano da administração Obama e permaneciam em baixa, no ano da posse de Trump. De acordo com uma pesquisa da rede CNN publicada pela revista Valor Econômico $(2017)^{8}$, a avaliação positiva do Partido Democrata atingia, no final de 2017, o menor índice em 25 anos. Os dados indicavam que 37\% dos americanos possuíam uma visão favorável sobre a legenda e o estudo ressaltava que esse número estava bem abaixo dos 44\% assinalados em março de 2017. Quando se observava a opinião dos eleitores que se definiam como independentes, 42\% tinham uma percepção desfavorável dos dois partidos, contra apenas $8 \%$ que diziam apoiar ambos.

A estratégia de Trump explorou esse quadro herdado do desgaste do período democrata com Obama e o contexto religioso, para fermentar e conduzir a eleição nos seus termos. A pesquisa publicada pela PewResearch (2016) durante a campanha da eleição estabeleceu o mapa do conservadorismo religioso nos EUA: era forte na região Sul, especialmente nos estados de Alabama, Mississipi, Tennessee e Louisiana, onde mais de 70\% das pessoas se declaravam altamente religiosas. Oklahoma, Utah e Texas aparecem com destaque nas grandes planícies, numa faixa em torno de $65 \%$. A rota conservadora menos religiosa concentrava-se no Alasca (45\%) e nos estados

${ }^{8}$ Informações extraídas de Valor Econômico, edição de 7 nov 2017. 
montanhosos. A primeira votação em Trump nessas regiões foi geralmente bem distribuída, em alguns casos concentrada 9 . As populações nas zonas rurais, subúrbios e pequenas cidades também tendiam a associar-se mais politicamente com a direita conservadora.

$\mathrm{Na}$ tentativa de responder às inquietações sobre o nível da relação entre a ideologia do trumpismo e a teoria do destino manifesto, consultamos outras pesquisas de fundo religioso e político. Em relatório publicado em $2016^{10}$ pela Pew Research, o relator da pesquisa, Gregory Smith, constatou que, durante a campanha eleitoral presidencial, os eleitores evangélicos eram motivados tanto pela oposição a Hillary Clinton quanto pelo apoio a Trump. As motivações religiosas não foram explicitamente categorizadas, mas puderam demonstrar que os fatores da fé são sublimados em meio a outras variáveis. Por exemplo, cerca de $35 \%$ dos eleitores evangélicos brancos que apoiavam Trump mencionaram que o faziam em parte porque ele não era Clinton, o que remonta ao velho conceito de "voto útil”. Por outro lado, outros 35\% citaram o próprio Trump como o principal motivo para apoiálo. Aproximadamente um terço dos apoiadores evangélicos de Trump também apontou suas posições incisivas como a principal razão para apoiá-lo e cerca de um quarto (26\%) mencionou seu status como um político externo que traria mudanças ao sistema político. Um em cada cinco disse que o apoiava por causa de sua personalidade e estilo "diga como é".

De fato, conservadores sociais identificados nas igrejas protestantes, instituições filantrópicas e associações voluntárias veem seus valores tradicionais sendo ameaçados pelo secularismo e, quando apontam o próprio Trump como razão para votar nele, podem ter manifestado implicitamente o apoio a um líder que poderia garantir a proteção desses valores. Mesmo assim, esse flagrante de pesquisa durante a eleição americana pode indicar que devemos considerar a narrativa messiânica do destino manifesto como mais presente na construção da política interna e externa dos EUA do que propriamente no resultado das convicções dos eleitores, e deve significar também que não vem isolada com conotações exclusivamente religiosas. Mesmo dentro do Partido Republicano não há evidências que tenha se tornado, até o fim do governo Trump, uma política de Governo com base na opinião dos eleitores.

Assim, devemos admitir que a experimentação democrática, conforme preconizada pelos fundadores, não é a única maneira de escapar à perdição fatal do republicanismo clássico, pois a experimentação democrática pode ser encontrada também na medula do destino manifesto, ainda que seguindo um modelo conservador. Nos aspectos políticos que exteriorizam o destino manifesto, cada presidente pode diluir esses pilares nas políticas externas em função de suas convicções ou da conjuntura político-econômica vigente. Em um artigo publicado em 2020 pela Foreign Affairs, Por que a América deve liderar novamente: resgatando a política externa dos EUA após Trump, o presidente Joe Biden reforçava o discurso missionário excepcionalista e moralista, que se refere à nação como distinta de todas as outras, defende uma nova liderança global encabeçada pelos EUA e

\footnotetext{
9 Informações extraídas de PewResearch.org (2016).
}

10 Idem. 
simultaneamente projeta plataformas de cooperação internacional multipolares para garantir a "supremacia do liberalismo e da democracia sobre o fascismo e o nazismo". Nesse contexto, na lógica do confronto político-ideológico, ele reitera que a ameaça aos EUA e ao mundo livre é a Rússia, retomando parcialmente o discurso conservador da Guerra-Fria.

Nas eleições de 2020, verificamos que a equação conservadora-republicana, que vinha trocando a cada oito anos com a equação liberal-democrata, sofrerá uma solução de continuidade, contudo, diante das afirmações de Biden e da complexa narrativa da trajetória do destino manifesto nos períodos conservadores e progressistas, não há garantias de que o seu governo assumirá ao final de seu mandato uma identidade casada no padrão democrata-liberal, como vinha ocorrendo desde Clinton.

*Artigo recebido em 20 de dezembro de 2020, aprovado em 13 de julho de 2021.

\section{REFERÊNCIAS}

ABERBACH, Joel; PEELE, Gillian (ed.) Crisis of conservatism: The Republican Party, the Conservative Movement, and American Politics After Bush. Oxford: Oxford University Press, 2011.

ADAMS, Henry. History of the United States of America during the administrations of Thomas Jefferson and James Madison: New York, 1889-1891, VI, p. 123.

APPLEBAUM, Anne. O crepúsculo da democracia: como o autoritarismo seduz e as amizades são desfeitas em nome da política. São Paulo: Record, 2021.

ARRAES, Virgilio. Gerald Ford: seus herdeiros ainda no poder. In: Meridiano 47 Boletim de Análise de Conjuntura em Relações Internacionais, Repositório Institucional da Universidade de Brasilia, $\mathrm{n}^{\mathrm{0}}$ 77, Dez. 2006. Disponível em: https://repositorio.unb.br/handle/10482/20887. Acesso em 30 set. 2021.

BIDEN Jr, Joseph R. Why America must lead again: rescuing U.S. foreign policy after Trump. Foreign Affairs, vol. 99; $\mathrm{n}^{\circ}$ 2, pp. 64-76, março-abril, 2020.

BROWN, Stuart Garry. The First Republicans: Political Philosophy and Public Policy in the Party of Jefferson and Madison, 1954

CASTEL, Albert E. The Presidency of Andrew Johnson. American Presidency Colection. Lawrence: The Regents Press of Kansas, 1979. 
CONSTANTINO, Rodrigo. Democracia na América. Disponível em: http://www.gazetadopovo.com.br/rodrigo-constantino/artigos/a-democracia-naamerica/. Acesso em 30 set. 2021.

CRITCHLOW, Donald. The Conservative Ascendancy: How the GOP Right Made Political History. Cambridge: Harvard University Press, 2007.

DAVIDSON, James West. Uma breve história dos Estados Unidos. 2. ed. Porto Alegre: L\&PM, 2016.

DIAMOND, Sara. Not by Politics Alone. New York: Guilford Press, 1998.

DICIONÁRIO SENSAgENT. Partido Whig Estados Unidos da América. Disponível em:

http://dicionario.sensagent.com/Partido\%20Whig\%20(Estados\%20Unidos\%20da\%20Am \%C3\%A9rica)/pt-pt. Acesso em 30 set. 2021.

ESTADOS UNIDOS. Presidente (2017-2020: Donald John Trump). Discurso de posse. Washington, Casa Branca, 20 jan. 2017. Disponível em: https://br.usembassy.gov/pt/discurso-de-posse-presidente-donald-j-trump/. Acesso em 30 set. 2021.

EKIRCH JÚNIOR, Arthur A. A democracia americana: teoria e prática. Rio de Janeiro: Zahar Editores, 1965.

EMERSON, Ralf Waldo. Círculos, 1841. EmersonCentral.com. Disponível em: https://emersoncentral.com/texts/essays-first-series/circles/. Acesso em 30 set. 2021.

FONSECA, Carlos. Deus está do nosso lado: excepcionalismo e religião nos EUA. Contexto Internacional, vol. 29, $\mathrm{n}^{0}$ 1, Rio de Janeiro, jan-jun 2007.

GELLMAN, Irwin; SMALL, Melvin. The Richard Nixon vice presidency: Research without the Nixon manuscripts. Blackwell Publishing Ltd., 2012

HIRSCHMAN, Albert. O. Shifting Involvements: Private Interest and Public Action. 20 ${ }^{\text {th }}$ anniversary ed. New Jersey: Princeton University Press, 1982, p. 3-8.

HOLMES, David L. The Faiths of the Founding Fathers. Oxford University Press, 2006, p. 13

HUDSON, Linda S. Mistress of Manifest Destiny: A Biography of Jane McManus Storm Cazneau, 1807-1878. Texas State Historical Association, 2001.

IORIS, Rafael. Republicanos evitaram o impeachment. Toparão ser o Partido de Trump? Carta Capital. Disponível em: https://www.cartacapital.com.br/artigo/republicanos-evitaram-o-impeachment-toparaoser-o-partido-de-trump/. Acesso em 30 set. 2021.

LAWSON, Alan. A Commonwealth of Hope: The New Deal Response to Crisis. Baltimore: The John Hopkins University Press, 2006. 
LEMOINE, Maurice. O pós-guerra imperial: em nome do destino manifesto. Le Monde Diplomatique Brasil, 2003. Disponível em https://diplomatique.org.br/em-nomedo-destino-manifesto. Acesso em 30 set. 2021.

MAGNOLI, Demétrio. O Corpo da Pátria: Imaginação geográfica e política externa do Brasil (1808-1912). São Paulo: Editora Moderna, 1997.

McClOSKY, Herbert.; ZALLER, John. O Ethos Americano: Atitudes Públicas para com o Capitalismo e a Democracia. Cambridge: Harvard University Press, 2013, 36op.

McGRATH, Alister. Historical Theology, An Introduction to the History of Christian Thought. Oxford: Blackwell Publishers, 1998. pp. 214-215.

MERK, Frederick. Manifest Destiny and Mission in American History: A Reinterpretation. Harvard University Press, 1995.

ROSENBLUN, Nancy L. Obligations of Citizenship and Demands of Faith: Religious Accommodation in Pluralist Democracies. Princeton University Press, 2000, p. 156

SCHLESINGER JUNIOR, Arthur. Os ciclos da história americana. Rio de Janeiro: Civilização Brasileira, 1992.

SCHNEIDER, Gregory. The Conservative Century: From Reaction to Revolution. Lanham: Rowman and Littlefield Publishers, Inc., 2009.

SMITH, Gregory A. Many evangelicals favor Trump because he is not Clinton. PewResearch, 2016. Disponível em: https://www.pewresearch.org/topics/2016election/page/9/. Acesso em 30 set. 2021.

TOCQUEVILlE, Alexis de. Democracia na América. 2 ed. São Paulo: Martins Fontes, 2005 .

VALOR ECONOMICO. Partido democrata tem a menor popularidade em 25 anos. Disponível em: https://www.valor.com.br/internacional/5185405/eua-partido-democratatem-menor-popularidade-em-25-anos-diz-pesquisa. Acesso em 30 set. 2021.

VIDAL, Camila. Liberalismo e Conservadorismo nos Estados Unidos: Construção e evolução no século XX. Campos Neutrais - Revista Latino-Americana de Relações Internacionais, vol. $1, \mathrm{n}^{0} 3$, p. 33-55, setembro-dezembro, 2019.

WEEKS, Willian Earl. Bulding the Continental Empire: American expansion from Revolution to the civil war. American Ways Series, 1997.

WEINER, Mark S. Understanding Trumpism: Politcs and Culture in an age of globalization. Revista de Direitos e Garantias, Vitória, v. 21, n. 2, p. 77-96, maio/ago, 2020. 